\title{
Tsafon
}

Revue d'études juives du Nord

$79 \mid 2020$

Les Juifs du Nord et du Pas-de-Calais dans la Shoah

\section{Haïm Vidal Sephiha (1923 - 2019)}

Le veilleur de la langue judéo-espagnole

Marie-Christine Bornes Varol

\section{CpenEdition}

Journals

Édition électronique

URL : https://journals.openedition.org/tsafon/2993

DOI : $10.4000 /$ tsafon.2993

ISSN : 2609-6420

Éditeur

Association Jean-Marie Delmaire

Édition imprimée

Date de publication : 1 juillet 2020

Pagination : 181-183

ISSN : 1149-6630

Référence électronique

Marie-Christine Bornes Varol, « Haïm Vidal Sephiha (1923 - 2019)», Tsafon [En ligne], 79 | 2020, mis en ligne le 01 juillet 2020, consulté le 28 juin 2021. URL : http://journals.openedition.org/tsafon/2993 ; DOI : https://doi.org/10.4000/tsafon.2993 


\title{
Hommage
}

\section{Haïm Vidal Sephiha (1923 - 2019)}

\author{
Le veilleur de la langue judéo-espagnole
}

\section{Marie-Christine Bornes Varol ${ }^{*}$}

Haïm Vidal Sephiha, professeur de linguistique hispanique, spécialiste du judéo-espagnol et professeur émérite de l'Inalco, s'est éteint le 17 décembre 2019 dans sa $97^{\mathrm{e}}$ année, après une vie de recherche entièrement consacrée au judéo-espagnol et au ladino.

Haïm Vidal Sephiha est né en 1923 à Bruxelles dans une famille judéo-espagnole originaire d'Istanbul. Après des études d'agronomie, interrompues par la guerre, il est déporté depuis la Belgique, en 1943, au camp d'Auschwitz Birkenau. Il survit à la Shoah et étudie la chimie à l'université de Bruxelles dont il sort diplômé en 1948.

Après la mort de sa mère en 1950, il décide de consacrer sa vie à l'étude du judéo-espagnol, la langue de sa famille. Il entreprend en 1953 des études de langue et littérature espagnole à l'Institut d'Études Hispaniques de la Sorbonne, suit les enseignements de Bernard Pottier, de David Cohen et les cours de I. S. Revah à l'École Pratique des Hautes Etudes (IV ${ }^{\mathrm{e}}$ section) puis au Collège de France.

Après un travail sur les traductions du Livre de Jérémie imprimées au XVI ${ }^{\mathrm{e}}$ siècle, il soutient, en 1970, une thèse de doctorat sur Le ladino,

\footnotetext{
* INALCO. Cet hommage a été rédigé pour le site de la Société des Hispanistes Français, consultable sur http://www.hispanistes.fr/. Nous remercions Madame Hélène Thieulin Pardo, présidente de la SHF pour nous avoir autorisé à le reproduire.
} 
judéo-espagnol calque - Deutéronome, versions de Constantinople, 1547 et de Ferrare, 1553 qui fut publiée en 1973 aux Éditions Hispaniques sous les auspices de Charles Vincent Aubrun. Haïm Vidal Sephiha y développe à partir de la Bible de Ferrare (1553) et du Pentateuque de Constantinople (1547) sa démonstration selon laquelle le ladino langue-calque de l'hébreu, liturgique et pédagogique - ne peut être confondu avec le judéo-espagnol vernaculaire, même s'il existe des influences mutuelles. La même année il fonde à l'École Pratique des Hautes Études (IV ${ }^{\mathrm{e}}$ section) des cours/ateliers destinés à former des chercheurs et à recueillir la parole, la langue et la littérature orale des Judéo-Espagnols.

Marqué par l'anéantissement de cette culture en Europe durant la Seconde Guerre mondiale, il multiplie les démarches en France et à l'étranger pour la sauvegarder partout où elle subsiste et publie aux éditions Entente en 1977 L'Agonie des Judéo-Espagnols, puis, en 1986, Le Judéo-espagnol. Il diffuse les travaux de Michael Molho et de Joseph Nehama sur Salonique, réédite l'ouvrage d'histoire de Moïse Franco sur les Israélites de l'Empire ottoman, publie le roman judéo-espagnol du salonicien Enrique Saporta y Beja.

Depuis 1968 il enseigne la linguistique hispanique à l'université de Paris 3 et assure depuis 1967 les cours de judéo-espagnol au sein du département d'hébreu de l'Inalco. Ses ateliers accueillent des chercheurs et des auteurs du monde entier et il publie de très nombreux articles dans des revues savantes (Bulletin de la Société Linguistique de Paris, Revue des Études Juives, Cahiers de Linguistique Hispanique Médiévale, Cahiers Balkaniques, Ibérica, International Journal of the Sociology of Language, Massorot...) et des volumes collectifs.

En 1979, il soutient à l'université de Paris 3 sa thèse d'état sur la théorie du ladino, Le Ladino - Structure et évolution d'une langue liturgique (éditée en 1982). La même année il fonde l'Association Vidas Largas «pour le maintien et la promotion de la langue et de la culture judéo-espagnoles », qui servira de référence dans le monde entier. L'association qui compte un grand nombre de membres, organise des ateliers, des cours et des conférences, édite un bulletin et des ouvrages, promeut des œuvres, des auteurs, des artistes, des projets. Présente à Paris, Lyon et Marseille, elle crée des émissions de radio à partir de 1981.

Cette année-là, Haïm Vidal Sephiha devient, à l'université de Paris 8, professeur des universités en linguistique hispanique et il obtient 
en 1984 le transfert de son poste à l'Inalco pour y ouvrir la première « chaire » entièrement dédiée à l'enseignement et à la recherche en langue, littérature et civilisation judéo-espagnoles. Il y enseignera jusqu'en 1992, date à laquelle il devient professeur émérite.

Il a dirigé de nombreuses thèses et travaux et n'a jamais cessé de poursuivre ses conférences et la publication d'articles sur la Shoah, le judéo-espagnol calque, auquel il réserve ombrageusement le nom de ladino (ce qui lui vaudra de nombreuses polémiques) et le judéo-espagnol vernaculaire de l'ex-Empire ottoman qu'il choisira d'appeler djudezmo et qu'il situe dans le prolongement de l'espagnol médiéval comme la haketiya du Maroc.

Deux hommages lui ont été consacrés : deux volumes de la revue Yod en 1992 et Hommage à Haïm Vidal Sephiha en 1997 (dirigé par W. Busse et M.-Ch. Varol Bornes chez Peter Lang). Il a publié en 2015 avec son fils Dominique Vidal un volume d'entretiens Ma vie pour le judéoespagnol aux éditions Bord De L'eau.

Avec lui, l'hispanisme perd un romaniste averti et le monde judéoespagnol un infatigable défenseur et un polémiste redoutable.

$* * * * * * * * * * * * * * * * * *$

Tsafon a publié son témoignage sur sa déportation et sa participation à une marche de la mort dans son $n^{\circ} 73$, printemps - été 2017, p. 29-38. 